\title{
A Super-Efficiency DEA Model with Preference to Evaluate Train Service Plan for High-Speed Railway
}

\author{
Zhenhuan $\mathrm{He}^{1, *}$, Liwei Zhang ${ }^{1}$, Lei $\mathrm{Nie}^{1}$ and Jianan Tong ${ }^{2}$ \\ ${ }^{1}$ School of Traffic and Transportation, Beijing Jiaotong University, Beijing 100044, China \\ ${ }^{2}$ China Railway Eryuan Engineering Group CO.LTD, Chengdu 610031, Sichuan China \\ ${ }^{*}$ Corresponding author
}

\begin{abstract}
We have developed and implemented a new method for evaluating train service plans. The basic idea of this super-efficiency DEA model with preference (SEP DEA) is to simultaneously consider the evaluation with selection of indicators, classification of indicators and indicator weight determination. The SEP DEA model is able to take into account the indicator preference and distinguish the difference in efficient service plans practically. The preferred DEA model, super-efficiency DEA model and SEP DEA model were respectively applied to evaluate three train service plans of Beijing-Guangzhou high-speed railway. We gave high weighs to the indicators of average travel time and ticket revenue. The results prove the new model could better distinguish the efficiency of all service plans and balance the input and output for the inefficient service plans. The new model is more suitable for the characteristics and the demand of real railway operation.
\end{abstract}

Keywords-railway operation; evaluation method; DEA model; train service plan; high-speed railway

\section{INTRODUCTION}

Train service plan (TSP) specifies the origin and destination stations of the trains, their stops at intermediate stations and capacity and frequency as well. It is the foundation of train operation in high-speed railway and its quality determines the efficiency and benefits of railway enterprise directly. The comprehensive and accurate evaluation of TSPs can give key advice about the direction for further optimization, which is very important both in theory and in practice. DEA model needs weak requirements and has strict mathematical reasoning process that can effectively avoid the impact of subjective factors so that it has been widely used in TSP related evaluation.

DEA method was proposed by Charnes, Cooper and Rhode in 1978 and it was designed to evaluate the relative efficiency of decision making units (DMUs) in the multiple input and multiple output mode. Preferred DEA model has been proposed by Charnes et al (1986), giving different weights to the indicators; however, the model does not distinguish the difference of efficient schemes which is a major concern in this research. Andersen and Petersen (1993) proposed an improved method, which was later called super-efficiency DEA model. Effective DMUs could be compared and ranked but this model does not follow the will of the people to consider the weight of the indicator, which is another concern in this research.

Qu et al. (2012) have evaluated the intercity TSP based on DEA model. Zhang et al. (2008) used DEA model to evaluate the passenger TSPs. Zhao et al. (2016) evaluated the transportation system coordinated development level of Beijing - Tianjin - Hebei. Weidong Wang et al. (2014) have evaluated the urban road traffic efficiency based on preferred DEA model, and the result was more accurate than that of DEA model. Mousavi et al. (2015) presented a super-efficiency data envelopment analysis model to perform an exhaustive comparative analysis of the most popular bankruptcy modeling frameworks in UK. Yang et al. (2015) measured environmental efficiency by super-efficiency data envelopment analysis model.

Based on the existing achievements, it will present a super-efficiency DEA model with preference (SEP DEA model) that evaluates the train service plan more accurately and efficiently, making full use of the advantages of preferred DEA model and super-efficiency DEA model.

The organization of this paper is as follows. Section 2 introduces the construction of SEP DEA model, and analyzes the model principle and characteristics. In section 3, the evaluation process with SEP DEA model are described step by step. An example analysis is then implemented and compared with preferred DEA model and super-efficiency DEA model to show the potential of the proposed model. The last section concludes the findings.

\section{SEP DEA MODEL}

DEA method is based on the premise of the known input and output decision making unit (DMU), using the linear programming model to construct the production frontier of the observed data and the projection of each DUM on the production frontier is the solution. And the relative efficiency of each DMU is determined according to the degree of deviation from the production frontier. For the evaluation of TSP, the DMU is generally the each plan.

Preferred DEA model and super-efficiency DEA model are widely used in current TSP evaluation. Preferred DEA model gives greater emphasis on railway or passenger-focused indicators. However, the model can be only used to distinguish whether the TSP is efficient, it is difficult to further analyze the difference between the efficient TSPs. On the contrary, super-efficiency DEA can be used to tell the difference of the efficient TSPs but the preferences of railway enterprise and passengers are ignored, which might bring some deviation to the evaluation results. Based on above characteristics, it will develop a SEP DEA model which inherits above advantages. 


\section{A. Construction of SEP DEA Model}

Assuming that there are $n$ TSPs and each one has $m$ input indicators and $s$ output indicators which are respectively denoted by $X_{j}=\left(x_{1 j}, x_{2 j}, \cdots, x_{m j}\right)^{\mathrm{T}}$ and $Y_{j}=\left(y_{1 j}, y_{2 j}, \cdots, y_{s j}\right)^{\mathrm{T}}$, where $x_{i j}$ is the $i$ th input index in the $j_{\text {th }}$ evaluation scheme; $y_{r j}$ is the $r$ th output index in the $j_{\text {th }}$ evaluation scheme; $X_{j}$ and $Y_{j}$ are the known data.

Then SEP DEA model can be constructed as following:

$$
\begin{gathered}
\text { min } z=\theta \\
\text { s.t. }\left\{\begin{array}{l}
\sum_{\substack{j=1 \\
j \neq k}}^{n} X_{j} \lambda_{j}-A^{\mathrm{T}} \partial+S^{-}=\theta X_{0} \\
\sum_{j=1}^{n} Y_{j} \lambda_{j}+B^{\mathrm{T}} \beta-S^{+}=Y_{0} \\
\lambda_{j} \geq 0, S^{-} \geq 0, S^{+} \geq 0 \\
\partial \geq 0, \beta \geq 0
\end{array}\right.
\end{gathered}
$$

Where:

$\theta$ is the efficiency;

$S^{-}$is the slack variable corresponding to the input;

$S^{+}$is the residual variable corresponding to the output;

$\lambda_{j}$ is the input and output index coefficient;

$A$ and $B$ are the coefficient matrices of input and output indicators weight constraints respectively;

$\partial$ and $\beta$ are the corresponding variables of the input and output indicators weight constraints.

The optimal solution of the model is $\theta^{*}, S^{*}$ and $S^{+^{*}}$, which can be used as following:

(1) When $\theta^{*} \geq 1$, the evaluation scheme is efficient. We can further distinguish the efficient schemes according to $\theta^{*}$. The larger the $\theta^{*}$ value is, the better the scheme is.

(2) When $\theta^{*}<1$, the evaluation scheme is inefficient, and the projection onto the efficient production frontier can be calculated:

$$
\begin{gathered}
X_{0}^{*}=\sum_{\substack{j=1 \\
j \neq k}}^{n} X_{j} \lambda^{*}{ }_{j}-A^{\mathrm{T}} \partial^{*}=\theta^{*} X_{0}-S^{-*} \\
Y_{0}^{*}=\sum_{\substack{j=1 \\
j \neq k}}^{n} Y_{j} \lambda^{*}{ }_{j}+B^{\mathrm{T}} \beta^{*}=Y_{0}+S^{4^{*}}
\end{gathered}
$$

And then we can calculate the redundancy ratio of the input indicators and the deficiency ratio of output indicators:

$$
\begin{gathered}
P_{x}=\frac{X_{0}-X_{0}^{*}}{X_{0}} \\
P_{y}=\frac{Y_{0}^{*}-Y_{0}}{Y_{0}}
\end{gathered}
$$

The results provide a reference for the adjustment of the train service plan.

\section{B. Principle and Characteristics of SEP DEA Model}

Compared with preferred DEA model, it's assumed that there are 4 TSPs: A, B, C, and D, in which A to C are efficient and $\mathrm{D}$ is inefficient by preferred DEA model. Figure 1 shows the principle of evaluation with preferred DEA model and SEP DEA model respectively described above.

As shown in Fig. 1 (a), in the process of evaluating with preferred DEA model, three efficient TSPs constitute the production frontier $A B C$. $D$ is an inefficient one which is surrounded by production frontier. $\mathrm{B}_{1}$ and $\mathrm{D}_{1}$ are the intersections of $\mathrm{OB}$ and $\mathrm{OD}$ on the production frontier $\mathrm{ABC}$, then the efficiency of TSP $\mathrm{B}$ is $\mathrm{OB}_{1} / \mathrm{OB}=1$. Similarly, the efficiency of TSP A and TSP C is also 1. And the efficiency of TSP D is $\mathrm{OD}_{1} / \mathrm{OD}<1$. That is, the efficiency of the TSP on the production frontier is equal to 1 , and the efficiency of the inefficient TSP is less than 1.

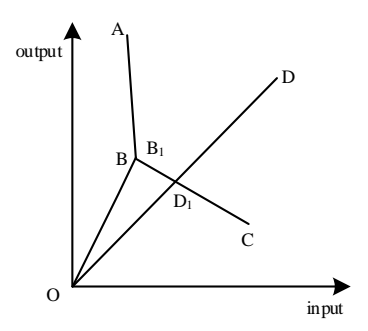

(a)

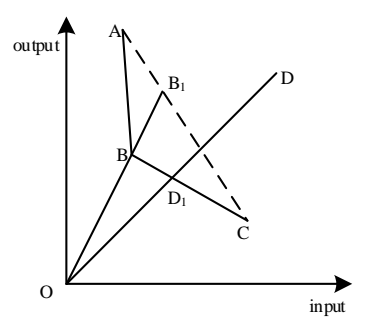

(b)
FIGURE I. PREFERRED DEA MODEL (B) SEP DEA MODEL

The evaluation process using SEP DEA model is shown in Fig. 1 (b). When the efficiency of TSP B is calculated, TSP B will be excluded from the reference set of the evaluation TSPs, and the efficient production frontier $\mathrm{ABC}$ becomes to AC. The efficiency of TSP $\mathrm{B}$ becomes $\mathrm{OB}_{1} / \mathrm{OB}>1$, where $\mathrm{BB}_{1}$ is called expandable ratio, which can be used to sort the TSPs. For example, the efficiency of TSP B is 1.2, which means it will be still efficient if all the input factors are increased by the same ratio of $20 \%$. Furthermore, TSP C is better than TSP B for the efficiency of TSP C is 1.5. And the efficiency of the original inefficient TSP D is unchanged because the production frontier has not changed for TSP D.

Compared with super-efficiency DEA model, SEP DEA model can give different weights to the input and output indicators. Suppose there are 3 TSPs. And there are four input indicators and three output indicators for the evaluation. When super-efficiency DEA model is used, the specific TSP indicator weights are automatically selected by the model in the evaluation process according to the most favorable principle of 
the DMU. These weights may be inconsistent with the relative importance of the indicators. In fact, the evaluator may wish to have the following preference for the weights of the input and output indicators:

$$
\left\{\begin{array}{l}
\omega_{1} \geq \omega_{3}, \omega_{1} \geq \omega_{4}, \omega_{2} \geq \omega_{3}, \omega_{2} \geq \omega_{4} \\
\mu_{1} \geq \mu_{3}, \mu_{2} \geq \mu_{3}
\end{array}\right.
$$

$w_{i}$ is the weight of $i$ th input index;

$u_{j}$ is the weight of $j_{\text {th }}$ output index;

In SEP DEA model, the coefficient matrix of input and output index weights is introduced to identify the importance of different indicators, so as to evaluate the efficiency of each TSP according to the willingness of the evaluator, and can better adapt to above evaluation requirements.

In summary, SEP DEA model is more advantageous compared with the other DEA models.

\section{EVAluation Process}

The main steps are as follows:

(1) Selection of indicators

Selection of evaluation indicators is the most critical step in the process. A TSP for High-speed railway has a lot of evaluation indicators generally and some of them have high correlations with each other. Therefore, the indicators used in the model must be selected reasonably. A clustering analysis method is used in the research to analyze the correlation between the indicators and some independent and representative indicators are selected finally to form the evaluation indicator system.

(2) Classification of indicators

After we determine the evaluation indicators, the input and output indicators need to be further classified. The input indicator refers to them the TSP needs to consume, such as total cost. The output indicator refers to the amount of information that indicates the efficiency of the TSP, generated after the input has been entered such as the total ticket revenue. According to the input-output principle, the less the better the input (negative indicators) and the more the better the output (positive indicators). So the negative indicators of TSP should be taken as input indicators, and the positive indicators should be the output indicators.

\section{(3) Indicator weight determination}

A matrix for the relative importance of the indicators each other will be constructed from the view of both the railway enterprises and the passenger. The final weight of the various indicators will be gotten from the matrix.

(4) Solving of the model

According to above conditions and the known data of TSPs, the model is solved to obtain the optimal solutions, $\theta^{*}, s^{-}$ and $S^{+}$. Then TSPs can be analyzed and compared according to formulation 2 to 5 . Some advice can be gotten according to $\theta^{*}, s^{*}$ and $s^{*^{*}}$.

\section{EXAMPLE ANALYSIS}

Based on above models, three TSPs for Beijing-Guangzhou high-speed railway in May 2013 (TSP 1), July (TSP 2) and November (TSP 3) respectively were evaluated in the research. The passenger data in July 2013 was used as the common passenger data so that the outcome of different TSPs was comparable. The passengers were assigned to the trains in the three TSPs respectively by the algorithm researched by our group (Lu Tong (2013), passenger flow assignment theory and methods of the High-speed railway passenger transport service plan) so that all the indicators could be calculated.

\section{A. Selection and Classification of Indicators}

This research constructed the evaluation indicators system referring to literatures (Siyuan Qu et.al. (2012), Yuzhao Zhang et.al. (2008) and Deng et.al (2006)). All the indicators were calculated according to the actual operating data of TSP in July 2013. The SPSS software was used to cluster the indicators, and the selected indicators whose correlation coefficient was greater than 0.82 were clustered into one group.

The clustering results were shown in Figure 2. A representative indicator in each category was selected as the input and output evaluation indicators ultimately, shown in Table 1.

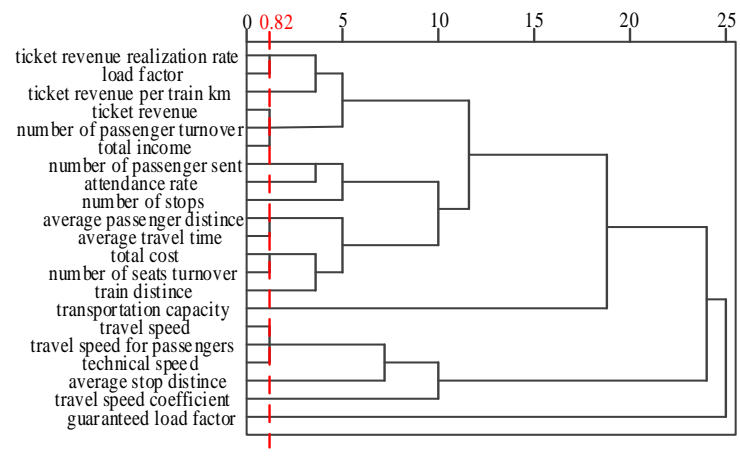

FIGURE II. CLUSTER ANALYSIS TREE OF EVALUATION INDICATORS

\section{B. Indicator Weight Determination}

In the actual evaluation process, it is necessary to determine the weights of various indicators from the views of both the passenger and the railway. For passengers, the quality of transport services is more vital. However, for railway enterprises, the operating costs and benefits should be paid more attention to. Considering the demand of both passengers and railway enterprises comprehensively, the weights of average travel time for passengers and the ticket revenue were increased that the weight of the average travel time is greater than other input indicators and the weight of the ticket revenue is greater than other output indicators. Taking into account various indicators, the weight sequence of the indicators were determined, shown as following: 
$\left\{\omega_{8} \geq \omega_{1}, \omega_{8} \geq \omega_{2}, \omega_{8} \geq \omega_{3}, \omega_{8} \geq \omega_{4}, \omega_{8} \geq \omega_{5}, \omega_{8} \geq \omega_{6}, \omega_{8} \geq \omega_{7}\right.$

$\left\{\mu_{1} \geq \mu_{2}, \mu_{1} \geq \mu_{3}, \mu_{1} \geq \mu_{4}, \mu_{1} \geq \mu_{5}, \mu_{1} \geq \mu_{6}, \mu_{1} \geq \mu_{7}, \mu_{1} \geq \mu_{8}, \mu_{1} \geq \mu_{9}\right.$

Then the coefficient matrix A of the input indicator weights and matrix B of the output indicator weights were achieved.

\begin{tabular}{|c|c|c|c|}
\hline \multirow{7}{*}{$A=$} & -10000001 & & $-1-1000000000$ \\
\hline & $0-100000001$ & & $10-1000000$ \\
\hline & $00-100001$ & & $100-100000$ \\
\hline & $000-10001$ & $B=$ & $1000-10000$ \\
\hline & $00000-10001$ & & $10000-1000$ \\
\hline & $00000-101$ & & $100000-100$ \\
\hline & $\begin{array}{lllllllllllllll}0 & 0 & 0 & 0 & 0 & 0 & -1 & 1\end{array}$ & & $10000000-10$ \\
\hline
\end{tabular}

TABLE I. EVALUATION INDICATOR SYSTEM OF TSPS

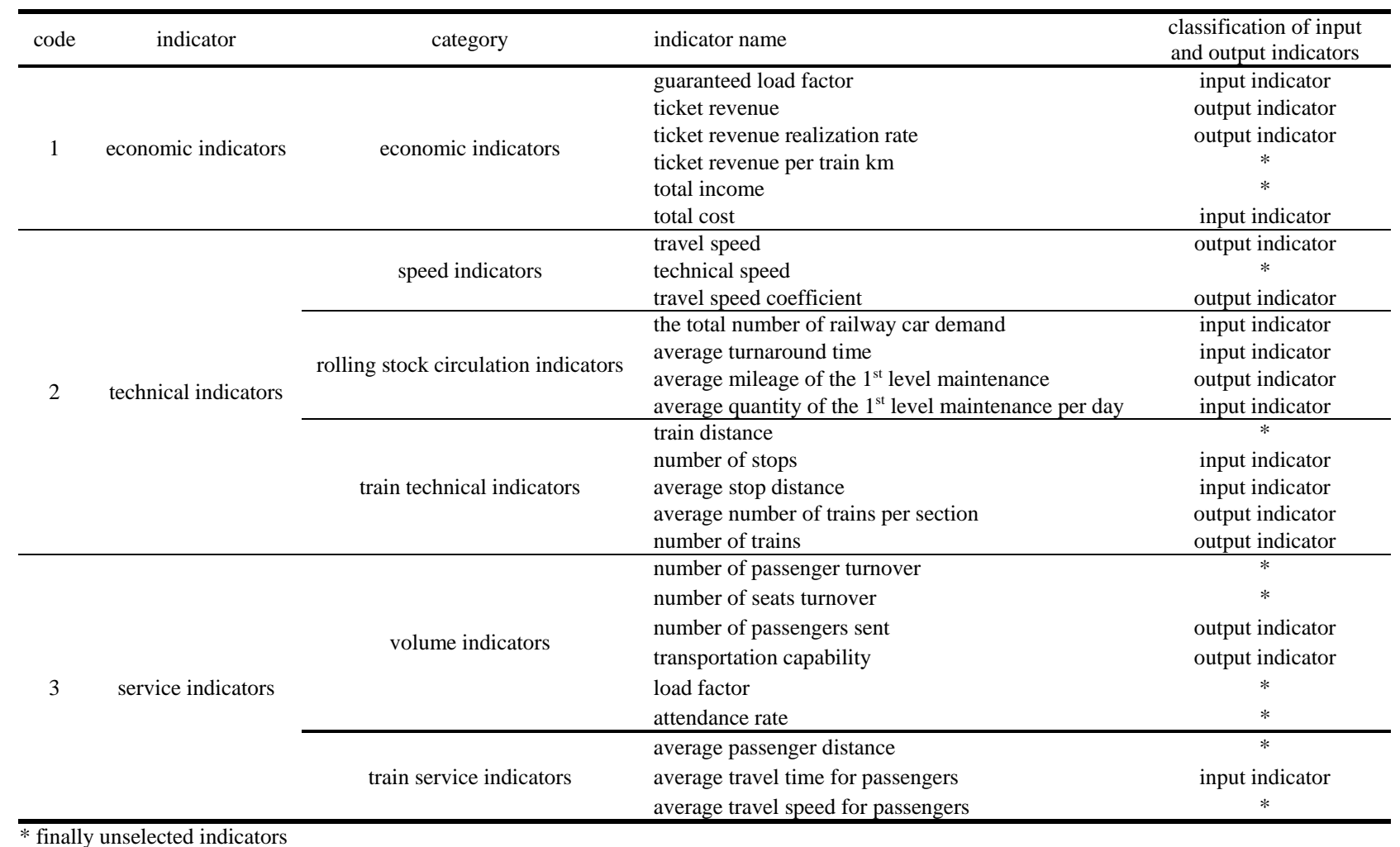

TABLE II. EVALUATION DATA FOR TSPS

\begin{tabular}{|c|c|c|c|c|}
\hline indicator characteristics & evaluation indicators & SP1 & SP2 & SP3 \\
\hline \multirow{8}{*}{ input indicators } & total cost / million & 4754.45 & 5943.06 & 5647.86 \\
\hline & guaranteed load factor & $51.93 \%$ & $64.91 \%$ & $63.50 \%$ \\
\hline & the total number of railway car demand / group & 109.60 & 137 & 125 \\
\hline & average turnaround time $/ \mathrm{h}$ & 1.34 & 1.43 & 1.41 \\
\hline & average quantity of the $1^{\text {st }}$ level maintenance per day & 110 & 121 & 112.50 \\
\hline & number of stops per train & 7.68 & 8.10 & 7.80 \\
\hline & average stop distance $/ \mathrm{km}$ & 142.86 & 134.83 & 142.11 \\
\hline & average travel time for passengers $/ \mathrm{h}$ & 2.64 & 2.80 & 2.50 \\
\hline \multirow{9}{*}{ output indicators } & ticket revenue / million & 5849.97 & 8357.10 & 8119.52 \\
\hline & ticket revenue realization rate & $56.06 \%$ & $65.80 \%$ & $69.48 \%$ \\
\hline & average number of trains per section & 43.19 & 61.71 & 60.10 \\
\hline & average travel speed $/ \mathrm{km} / \mathrm{h}$ & 194.63 & 220.90 & 225.93 \\
\hline & travel speed coefficient & 0.84 & 0.91 & 0.92 \\
\hline & average mileage of the $1^{\text {st }}$ level maintenance $/ \mathrm{km}$ & 2185.96 & 3122.80 & 3339.20 \\
\hline & number of trains / pair & 105 & 150 & 145 \\
\hline & transportation capability & 178096 & 254423 & 251608 \\
\hline & number of passengers sent & 234339 & 291914 & 295150 \\
\hline
\end{tabular}




\section{Solving of the Model}

The evaluation indicators were calculated on the basis of above analysis, shown in Table 2.

SEP DEA model, preferred DEA model and super-efficiency DEA model were used to evaluate 3 TSPs respectively. The results were shown in Table 3.

TABLE III. MODEL SOLUTION RESULTS

\begin{tabular}{cccc}
\hline \multirow{2}{*}{ Models } & \multicolumn{3}{c}{ efficiency value } \\
\cline { 2 - 4 } & TSP1 & TSP2 & TSP3 \\
\hline preferred DEA model & 0.9993 & 1.0000 & 1.0000 \\
super-efficiency DEA model & 0.9993 & 1.2913 & 1.1976 \\
SEP DEA model & 0.9993 & 1.0903 & 1.1719 \\
\hline
\end{tabular}

\section{Results Analysis}

The efficiency of TSP 1 is always less than 1 in the results of different models, which means that TSP 1 is surely an inefficient service plan. From the number of passenger sent, ticket revenue and the number of trains and other indicators can be seen (table 2), SP 1 with less input resources resulted in a large number of passenger loss, seriously affecting business efficiency. Eventually leading to TSP1 inefficient.

According to the efficiency values in table 3, both TSP 2 and TSP 3 were efficient. However, the efficiency of TSP 3 was larger than that of TSP 2 in the result of SEP DEA model, which was opposite to the result of super-efficiency DEA model. When analyzing of the values of indicators in Table 2, it could be found that the ticket revenue of TSP 2 increased by about $2.9 \%$ than that of TSP 3, but the quantity of EMU increased by $9.6 \%$, the $1^{\text {st }}$ level maintenance times increased by $7.5 \%$ and the other costs were also increased to varying degrees. Therefore, in fact, the TSP 3 is relatively better. The above results showed that after considering the indicator preference, the evaluation result was more in line with the actual operation demands.

In addition, for the inefficient TSP 1, further analysis on the projection could be done according to the results from SEP DEA model. Table 4 listed the relatively large redundant input indicators and deficient output indicators of TSP 1.

TABLE IV. REDUNDANT INPUT AND OUTPUT DEFICIENCY RATIO OF TSP 1

\begin{tabular}{|c|c|c|c|c|c|c|}
\hline \multicolumn{4}{|c|}{ redundant input ratio } & \multicolumn{3}{|c|}{ output deficiency ratio } \\
\hline $\begin{array}{l}\text { average quantity of the } 1^{\text {st }} \text { level } \\
\text { EMU maintenance per day }\end{array}$ & $\begin{array}{l}\text { number of } \\
\text { stops }\end{array}$ & $\begin{array}{l}\text { average stop } \\
\text { distance }\end{array}$ & $\begin{array}{l}\text { average travel time } \\
\text { for passengers }\end{array}$ & $\begin{array}{l}\text { ticket } \\
\text { revenue }\end{array}$ & $\begin{array}{l}\text { average mileage of the } 1^{\text {st }} \\
\text { level EMU maintenance }\end{array}$ & $\begin{array}{l}\text { transportation } \\
\text { capability }\end{array}$ \\
\hline $16.42 \%$ & $16.91 \%$ & $18.71 \%$ & $24.24 \%$ & $15.85 \%$ & $11.12 \%$ & $12.43 \%$ \\
\hline
\end{tabular}

The input of redundant indicators could be adjusted according to the above result in order to balance the input and output of TSP1 and, thus, some improving advices could be provided.

\section{V.CONCLUSIONS}

In this paper, SEP DEA model was proposed for the evaluation of train service plan on the basis of briefly analyzing of advantages and disadvantages of preferred DEA model and super-efficiency DEA model. Comparing to the latter two models, SEP DEA model combined their advantages and could recognize the efficiency of TSPs and, meanwhile, sort them. The preference of passengers and railway enterprise could be considered in the model in order to make the evaluation result in accordance with the actual operation demands.

Finally, three train service plans of Beijing-Guangzhou high-speed railway were taken as the evaluation objects and the evaluations were made with the three types of DEA model respectively. The results show that SEP DEA model is efficient and more reasonable. It could provide some macroscopic quantified advices for the further improvement of train service plan.

\section{ACKNOWLEDGEMENTS}

This work was supported by the Science and Technology Department of China Railway Corporation (2016X005-C) and the Joint Funds of the National Natural Science Foundation of China (NO.U1434207).

\section{REFERENCES}

[1] Charnes A, Cooper W W. (1978) and Rhode E. Meaning the efficiency of decision making units. European Journal of Operational Research, 6(2): 429-444.

[2] Charnes A, Cooper W W and Wei QL. (1986), A semi-infinite multi-criteria programming Approach to data envelopment analysis with infinitely many decision making units. The University of Texas at Austin, Center for Cybernetic Studies Report CCS 551.

[3] Andersen, P., Petersen, N.C. (1993), A procedure for ranking efficient units in data envelopment analysis. Management Science, 39, 1261-1264.

[4] Qu SY, Xu XF, Liu HD. (2012). Evaluation of train service planning of inter city railway based on DEA [J]. Journal of East China Jiaotong University, 29(1): 80-81.

[5] Zhang YZ, Zhang HW. (2008). DEA analysis and evaluation of passenger train service planning [J]. Journal of Lanzhou Jiaotong University, 27(6): 83-85.

[6] Liu L, Zhao GJ. (2013). Efficiency evaluation of high-speed railway passenger transport in China based on DEA method [J]. Journal of Dalian Jiaotong University, 34(3): 44-47.

[7] Deng LB, Shi F. (2006). Evaluation index system of passenger train service planning [J]. China Railway Science, 27(3): 106-108.

[8] Zhao LQ, Liu JY, (2016). DEA Evaluation of Coordinated Development Degree of Beijing - Tianjin - Hebei Transportation System. Journal of Beijing University of Technology, 40(1), 124-127.

[9] Wang WD, Wang J, Wu J, et al. (2014). Highway Traffic Efficiency Evaluation of Chang-Zhu-Tan Urban Agglomeration Based on DEA model [J]. Journal of Beijing University of Technology, 40(12): 1852-1853.

[10] Li T, Liu ZC, Zhang Y, et al. (2014). Evaluation of regional innovation efficiency of Jiangsu Province Based on DEA model with preference [J]. Henan Science, 32(6): 1098-1099. 
[11] Mousavi MM, Ouenniche J, Xu B (2015). Performance evaluation of bankruptcy prediction models: an orientation-free super-efficiency DEA-based framework. Int Rev Financ Anal 42: 64-75.

[12] Yang L, Ouyang H, Fang K, Ye L, Zhang J (2015) Evaluation of regional environmental efficiencies in China based on super-efficiency-DEA. Ecol Indic 51: 13-19.

[13] Fu LN, Chen XH, Leng ZH. (2013). Study on the ecological efficiency of Urban Agglomeration Based on super-efficiency DEA model [J]. China Population Resources and Environment, 23(4): 169-170.

[14] Chen TS. (2009). A based on cross data envelopment analysis method to evaluate operation efficiency of rail transportation system [J]. Journal of Beijing Jiaotong University, 8(1): 52-53.

[15] Tong L (2013). Passenger flow assignment theory and methods of the High-speed railway passenger transport service planning [D]. Beijing Jiaotong University, 57-82. 